\title{
Modern environmental technologies of healthy soils contaminated by heavy metals and radionuclides
}

\author{
Vasyl Savosko ${ }^{1, *}$, Aleksandr Podolyak $^{2}$, Irina Komarova ${ }^{1}$, and Aleksey Karpenko ${ }^{3}$ \\ ${ }^{1}$ Kryvyi Rih State Pedagogical University, Kryvyi Rih, 50086, Ukraine \\ ${ }^{2}$ Gomel Region Planning and Surveying Station of Agricultural Chemicalization, Gomel, 246029, Belarus \\ ${ }^{3}$ Francisk Skorina Gomel State University, Gomel, 246019, Belarus
}

\begin{abstract}
Object of research: to systematize (taking into account the possible consequences to biosphere) the known technologies for ecological restoration of soils contaminated by heavy metals and radionuclides. Only a healing technology should be recognized as one possible methodology for solving any soil problems. For soils contaminated by heavy metals and radionuclides healing patterns is conceptually ordered into the following levels: mission, strategy, technology. The mission of healthy soil should be aimed at maintaining the chemical elements content within the optimum interval. The strategy of healthy soil involves the regulation of individual elements content in the soil. Ex-situ a soil healing technology is implemented outside the original pollution site. In-situ, a soil healing technology is carried out directly on the original pollution site. Excavation of the contaminated soil layer is the first stage for ex-situ soil restoration. In the future it will be possible: 1) storage of contaminated soil at special landfills, 2) treatment of contaminated soil at a special reactor. All technologies for in-situ healthy of heavy metals contaminated soils can be ordered as: 1) localization, 2) deconcentration, 3) inactivation, 4) extraction.
\end{abstract}

\section{Introduction}

Soil, as an indispensable component of the biosphere, plays a crucial role in solving the problem of Human \& Nature interaction. It is the soil, as well as its unique ecological properties that shape the conditions and provide the means of existence for human civilization [8, $20,30,34,43]$.

The large accumulation of pollutants in soils is the most urgent task for modern soil science. Among the soil pollutants, heavy metals and radionuclides are the most dangerous to human health. On the 21 st century, the total area of contaminated land by these political agents is estimated in millions of hectares. In soil the heavy metals' half-life is hundreds and thousands of years, and the radionuclides' half-life is tens and hundreds of thousands of years $[21,24,28,38,44]$. That's why, multiple studies were performed to technology development for cleaning the soil, contaminated with heavy metals and radionuclides. However, the proposed contaminated soil cleaning technologies have a clearly anthropocentric character $[1,4,23,26,45]$.

At the same time, possible consequences for living organisms and soil from a new technology for a contaminated land restoration introduction were left without due attention $[3,18,24,36,46]$.

Object of research: to systematize (taking into account the possible consequences to biosphere) the known technologies for ecological restoration of soils contaminated by heavy metals and radionuclides.

\section{Materials and methods}

As the materials of this work were used: 1) own longterm research results; 2) modern scientific publications, which contain: a) real achievements in soil ecology / biospherology, b) data on successful technologies for restoration / purification / rehabilitation of soils contaminated by heavy metals and radionuclides.

In this work, research methods such as analysis and synthesis, induction and deduction, analogy and formalization, abstraction and concretization, classification and modeling were used.

\section{Results and discussion}

We believe that the concept of sustainable development is the main paradigm for modern soil science. However, for the successful implementation of this concept in soil science, soil must be considered as: 1) the object of production, 2) a component of the human habitat, 3) the functional of the biosphere.

\subsection{Principal model of the healthy soil}

We believe that, the known and tested technologies for restoration of contaminated soil have exclusively

${ }^{*}$ Corresponding author: savosko1970@gmail.com 
anthropocentric character. Since in most cases, they are aimed at solving the problems of society - the negative consequences for humans of the excessive pollutants content in soils to reduce. Whereas, modern technologies for restoration of contaminated soil should be based solely on the principles of pedosphere.

Therefore, the one possible methodology for solving any soil problem should be recognized only as a healing technology. As applied to heavy metals and radionuclides, soil improvement should include 1) elimination of negative consequences for the biosphere and humanity from the presence of these pollutants in soils, 2) unconditional preservation of soil functioning parameters within the limits of naturally acceptable norms. It is important to clarify that in solving any environmental problem, ignoring the conservation of soil health is possible only in exceptional cases (for example, the presence of a direct threat to human health). However, after eliminating the negative consequences of the soil pollutants action, measures are necessary for a soil properties and soil health regeneration.

In our opinion [27, 28, 29, 30, 48] for soils contaminated by heavy metals and radionuclides healing pattern is ordered conceptually into the following levels: mission, strategy, technology. The mission of healthy soil should be aimed at maintaining the chemical elements content within the optimum interval. The strategy of healthy soil involves the regulation of individual elements content in the soil. With a lack of certain metals (as nutrients), it is advisable to add metals to the soil (as fertilizer). With excessive content of heavy metals and radionuclides in the soil, it is necessary to eliminate and / or limit their negative impact on soil, biota, farm animals and humans. It must be emphasized that soil healing technologies involve of two measures implementation, which vary in location. In the first case (ex situ) a soil healing technology are implemented outside the original pollution site. In the second case (in situ), a soil healing technology are carried out directly on the original pollution site.

\subsection{Ex situ healthy of contaminated soil}

Excavation of the contaminated soil layer is the first stage for ex-situ soil restoration (Fig. 1). For this purpose, only the upper soil layers $(0-5 \mathrm{~cm}$, maximum 0 $20 \mathrm{~cm}$ ) are usually removed, since in these soil layers a prohibitive heavy metals / radionuclide content was usually $[2,5,7,11,49]$.

In the future, two systems of activities can be implemented. The first technology is the storage of contaminated soil at special landfills. The second technology is the treatment of contaminated soil at a special reactor.

Storage of contaminated soil can be performed: a) with preliminary treatment by special reagents that reduce the mobility of pollutants in the soil (lime, phosphogypsum, carbonates), b) without preliminary treatment $[6,9,15,19,47]$.
The technology of storing contaminated soil, as a method of healing contaminated lands, has numerous applications in world practice. However, this technique does not solve the problem of the presence of pollutants in the soil, but only "preserves it." That is why the widespread use of the storing heavy metals contaminated soil method is inappropriate. However, exceptions are possible - in limited areas, which are of very great importance. While for radionuclides, most likely this is the most likely way to improve excessively contaminated soil.

As we noted earlier, the second technology is the treatment of contaminated soil at a special reactor. In our case, only metals can be removed, therefore this method is called "demetalization". For this purpose, it was used [30]: 1) physical (hydrocyclonation, separation by density gradient, sonication), 2) chemical (washing with reagents, flotation), 3) physicochemical (electrochemical leaching), 4) biological (microleaching) techniques for contaminated soil demetallization (Fig. 1).

According to scientific literature date $[10,13,25,49$, 51], soil demetallization technologies are characterized by: 1) a high degree of metal recovery (in some cases up to $95-95 \%$ ); 2) low productivity of installations (from 10 to 300 tons of soil per day); 3) the high cost of cleaning (100-450 USD per $1 \mathrm{~m} 3$ of soil). It is also necessary to note that a soil that has undergone a full treatment cycle often loses a number of its leading properties. Therefore, after contaminated soil demetallization it is very necessary to apply techniques to restore soil fertility. Only after this, the cleared soil can be returned to its former place of residence.

\subsection{In situ healthy of contaminated soil}

\subsubsection{Environmental healthy of metals' contaminated soil}

In our opinion, all possible technologies for in-situ healthy of heavy metals contaminated soils can be ordered as: 1) localization, 2) deconcentration, 3 ) inactivation, 4) extraction (Fig. 2).

Localization is a technology that involves spatial limitation to increase the area of pollution. Localization has three directions: 1) phytolocalization, 2) technolocalization, 3) chemolocalization [30, 50].

Phytolocalization involves limiting the distribution of metals as a result of creating an artificial vegetation cover: grassy or woody. At the same time, the success of phytolocalization is determined by the combined action of two factors: the edaphic conditions of the contaminated area, and the selection of plants. To increase the efficiency of phytolocalization, it is recommended to use several ameliorants.

Technolocalization involves limiting the spread of metals from contaminated areas using mechanical barriers. At the same time, depending on the location and technology of creating such barriers, there are: mulching and the formation of techno-curtains. 


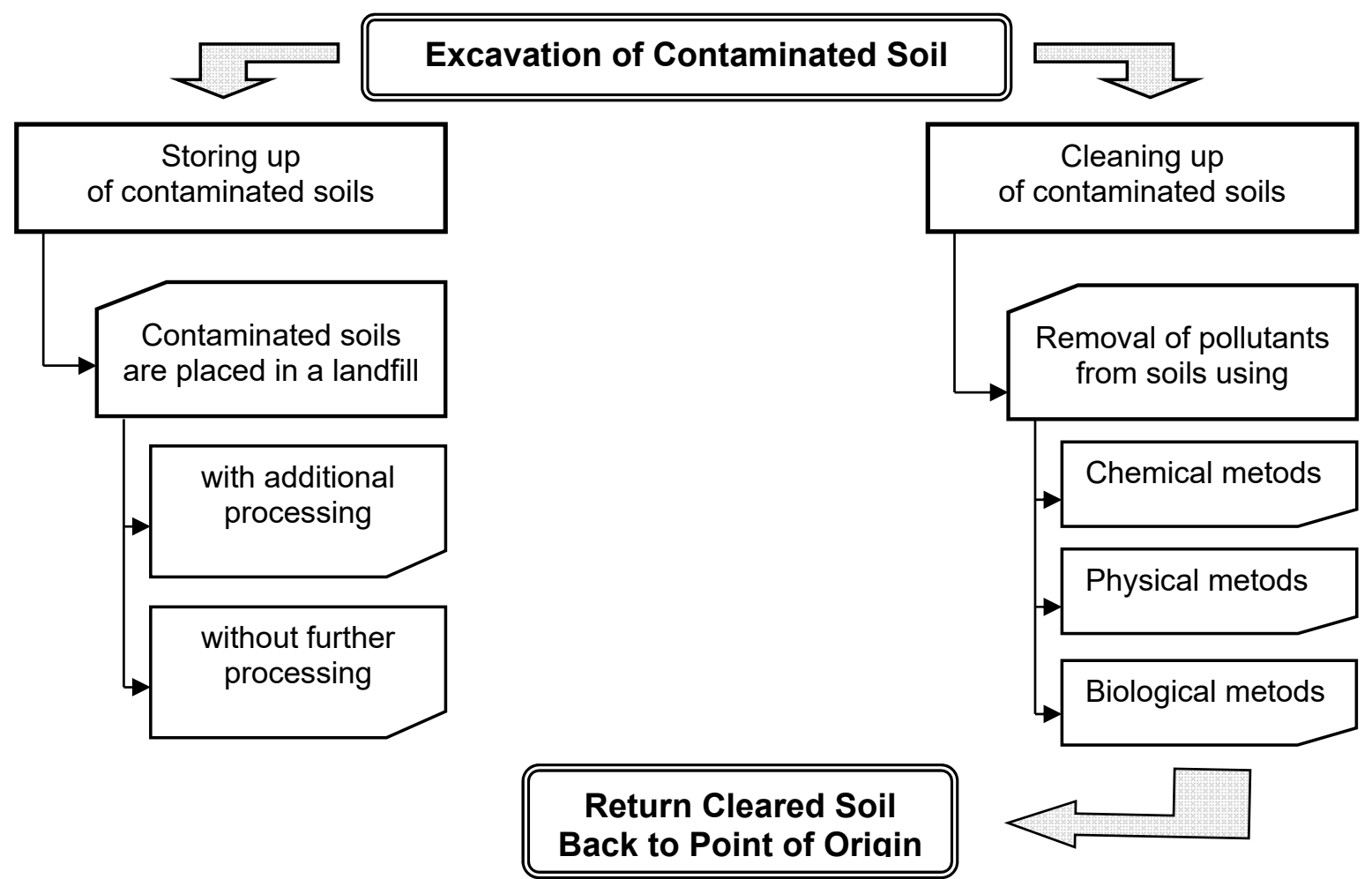

Fig. 1. Concept pattern "ex situ healthy soils contaminated by heavy metals and radionuclides".

\section{Technology, Methods \& Techniques}
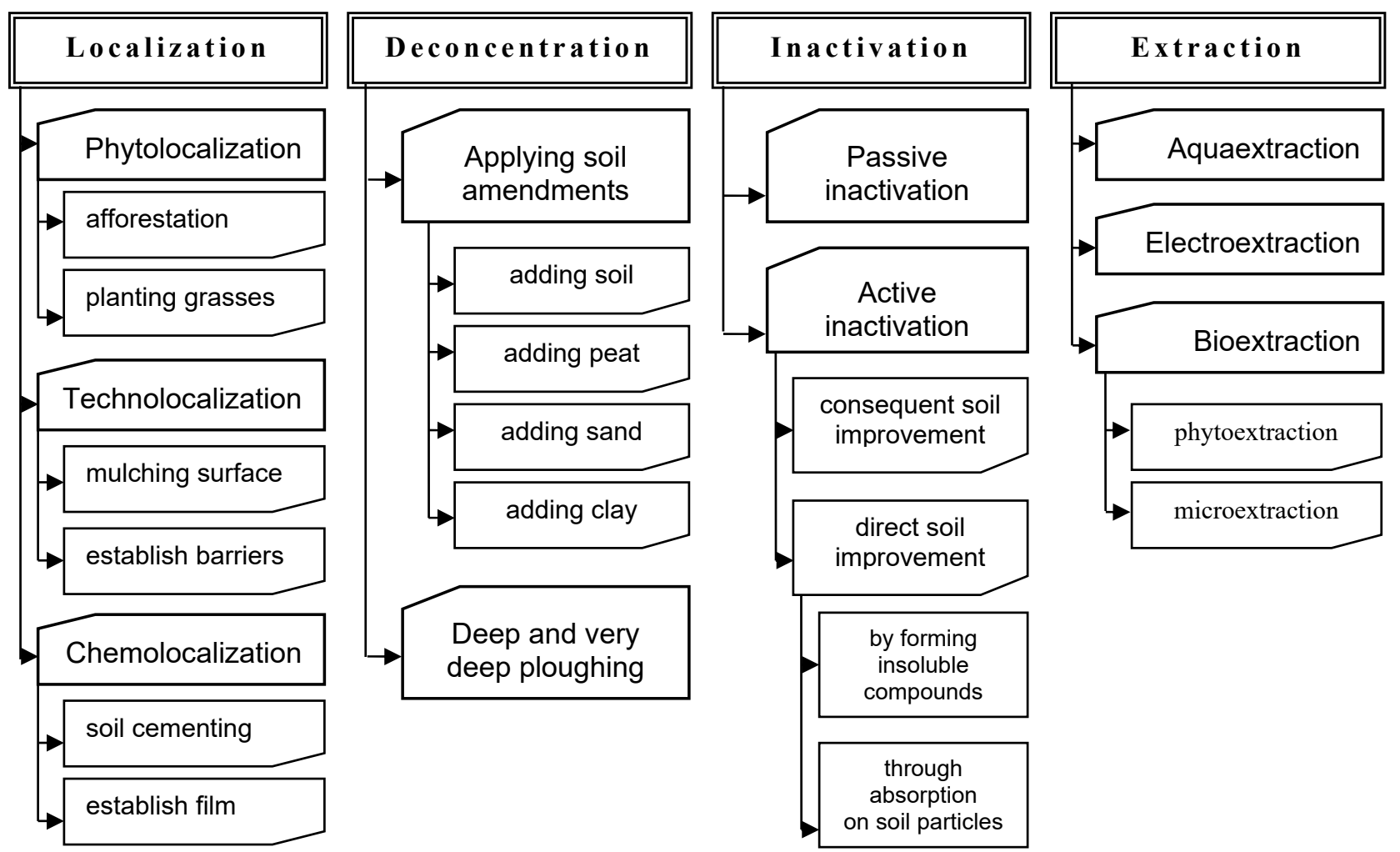

Fig. 2. Concept pattern "In situ healthy soils contaminated by heavy metals". 
Chemolocalization involves limiting the distribution of metals from contaminated territory, with the help of obstacles formed as a result of chemical reactions. Depending on the place of the reaction and the chemism of the formation of such barriers, chemolocalization is divided into: subsurface cementing and the creation of a protective film. The technology of subsurface cementing involves the introduction of special reagents into the soil, which determines the chemical bonding of pollutants and the formation of special granules. The technology for creating a protective film involves applying special substances to the surface of contaminated soil, which, as a result of chemical interaction with each other, as well as with soil components, form a stable coating. Such a coating, isolating the contaminated soil surface from the action of wind and precipitation, prevents the emission of pollutants as a result of erosion [30].

Deconcentration is a technology that involves mixing the contaminated soil horizon with uncontaminated soil layers and / or loose soil-like substrates. As a result, there is a decrease in the concentration of metals in soils. In practice, two methods of deconcentration of metals in soils are possible: 1) application of soil-like substrates, 2) deep plowing (Fig. 2).

Inactivation is a technology that involves the transfer of metals from the active (liquid phase of the soil) to inactive (solid phase of the soil). Inactivation of metals is divided into passive and active (Fig. 2).

The principle of passive inactivation of metals is to restore the natural fertility of the soil. The principle of active inactivation is the direct transition of metals to inactive forms due to: 1) the occurrence of certain pedogeochemical reactions, 2) the creation of special pedogeochemical conditions. In the first case, technologies of active direct inactivation of metals are implemented. The second implements technologies of active indirect inactivation of metals [12, 14, 32, 51].

It is promising to use: 1) clay content of a substance, 2) humic substances, 3) phosphate compounds, 4) calcareous materials, 5) industrial waste products, 6) specially synthesized substances for active direct inactivation of metals in soils. For active indirect inactivation of metals in soils, it is promising to use: 1) organic fertilizers (manure, peat, compost), 2) mineral fertilizers, 3) chemical reclamation reagents (lime, gypsum).

Extraction - those technologies that are aimed at the complete extraction of metals from the soil. The extraction of metals from the soil can be realized as: 1) aqua extraction, 2) electroextraction and 3) bioextraction (Fig. 2).

Aqua-extraction involves translocation of metals from contaminated soil layers beyond the soil profile using water and / or aqueous solutions of special reagents.

Electroextraction involves the extraction of metals from the soil due to the action of chemical reactions that obey electrokinetic's laws. Fundamentally, this technology is based on the directional movement of metals in the presence of an external electric field.

Bioextraction is based on the ability of living organisms in the process of their life to extract from the soil and accumulate metals in their bodies. As a result, there is a process of translocation of anthropogenic metals in the direction of "soil - living organisms". Bioextraction should be divided into: phytoextraction, zooextraction, microextraction and fungiextraction. However, in practice, bioextraction is represented mainly by two technologies: phytoextraction and microbextraction.

Phytoextraction is based on the natural ability of plants to absorb from the environment and accumulate metals in their tissues. As a result, directional translocation of metals from the soil to the aboveground phytomass occurs, which eventually collects and moves away from the territory. The result - the concentration of metals in the soil is gradually reduced to the required level. Studies of the last 20-25 years have shown that about 400 plant species from 45 families can be considered as metal hyperaccumulators [29, 30, 42, 43].

An innovative way to increase the efficiency of phytoextraction of metals from soils is the use of chemicals that significantly increase the flow of metals in the Soil - Plants system. Such substances are called "activators" or "effectors" for the phytoextraction of metals from soils $[4,10,30]$.

In the global perspective, it is possible to use phytoextractors enriched with biomass metals as phytogenic raw materials for the enrichment industry. Therefore, in the future, a wide-scale application of phyto-ore and phyto-mining technologies is possible.

Microextraction is a technology that is based on the use of the natural abilities of microorganisms as metal acceptors.

In this regard, it is assumed that there will be a targeted extraction of pollutants from the soil with their subsequent accumulation in microorganisms.

Microorganisms are able to extract metals from the soil as a result of reactions: adsorption, precipitation and oxidation; changes in the valence of metals, extracellular chemical deposition, volatilization; oxidation, immobilization and binding; binding, changes in the valence of metals, volatilization, extracellular chemical deposition and symbiosis with plants $[6,13,43,47,51]$.

\subsubsection{Environmental healthy of radionuclides' contaminated soil}

The radiation background following the Chernobyl nuclear power plant (ChNPP) accident in April 1986 was determined by 21 radionuclides. Most of them fell out with fine carbon particles (with adsorbed metal atoms condensation forms), as well as in the form of fuel particles. The greatest danger to living organisms was represented by a biologically active radionuclides group: ${ }^{131} \mathrm{I} ;{ }^{90} \mathrm{Sr} ;{ }^{137} \mathrm{Cs}$; ${ }^{238,239}{ }^{240} \mathrm{Pu} ;{ }^{141} \mathrm{Ce} ;{ }^{144} \mathrm{Pr} ;{ }^{103,106} \mathrm{Ru} ;{ }^{95} \mathrm{Zr}$; ${ }^{95} \mathrm{Nb}$. Heterogeneous in their dosimetric characteristics, these radionuclides have one thing in common: most of them are counterparts, analogues of chemical elements that perform important biological functions in living organisms and plants $[16,17,22]$.

Radioisotopes with a long half-life are especially dangerous. This group includes such surface pollutants 
as ${ }^{90} \mathrm{Sr},{ }^{137} \mathrm{Cs},{ }^{241} \mathrm{Am}$ and all plutonium isotopes. ${ }^{137} \mathrm{Cs}$ and ${ }^{90} \mathrm{Sr}$ pose the greatest danger to humans, animals and plants. They are easily integrated into trophic chains and are sources of internal and external irradiation of organisms. It is known that ${ }^{90} \mathrm{Sr}$. is an analogue of $\mathrm{Ca}$ and ${ }^{137} \mathrm{Cs}$ is $\mathrm{K}$. They are well soluble in water, easily absorbed by soil and are biologically mobile in agricultural chains, and have a long half-life $\left(\mathrm{T}_{1 / 2}\left({ }^{137} \mathrm{Cs}\right)=30,7\right.$ years; $\mathrm{T}_{1 / 2}\left({ }^{90} \mathrm{Sr}\right)=28,1$ years $)[2,7,9]$.

${ }^{137} \mathrm{Cs}$ is one of the major dose-forming radionuclides among fission products. An important feature of this isotope is the ability, along with exchange binding, to solid phase soil sorption (fixation), in particular, entry into interpacket spaces and fixation of $\mathrm{Cs}^{+}$ions by a crystal lattice of some secondary clay minerals. Firmly fixed $\mathrm{Cs}^{+}$ions are less likely to be converted into soil solution and therefore become less accessible to most crops. Unlike ${ }^{137} \mathrm{Cs}$, the main mechanism of absorption of ${ }^{90} \mathrm{Sr}$ by the solid phase of soil is ion exchange. The sorption of this radionuclide by the solid phase of the main soil types depends on the presence of macroconcentrations of other cations and anions in the soil solution $[11,15,22,36]$.

According to N. V. Timofeev-Resovsky [39, 40], the availability of radionuclides for plants depends primarily on soil properties and their behavior in soil (soil chemistry of radionuclides). The absorption of radionuclides by soil is determined by their distribution between the solid phase of the soil and the soil solution and is carried out at the expense of the processes of sorption - desorption, precipitation-dissolution of difficult-soluble compounds and coagulation peptization of colloidal particles. The formation and dissolution of precipitation depends on the ionic composition, $\mathrm{pH}$, Eh of the soil solution, and the presence of organic and inorganic acids. Adsorption of radionuclides from soil solution by solid phase of soil is closely related to the properties of mineral, organic and organomineral colloids [33, 35].

The behavior of cesium isotopes $\left({ }^{134} \mathrm{Cs}\right.$ and $\left.{ }^{137} \mathrm{Cs}\right)$ is determined by the fact that they are radioisotopes of an alkaline element having an oxidation degree of only +1 in any component of the natural environment. One of the most important features of these isotopes is the ability to invariably adsorb (fix) the solid phase of the soil, leading to a decrease in soil motility and a decrease in plant accumulation. The combination of soil-chemical (crystal-chemical) reactions leading to a decrease in the mobility of radionuclides in the soil due to their entry into the interpackage spaces of secondary minerals is commonly called "aging" [31, 37, 41].

The absorption and strength of ${ }^{137} \mathrm{Cs}$ by soil are significantly influenced by the content of $\mathrm{K}^{+}$ions and the presence of other competing cations in the soil solution. Thus, substitution in the soil-absorbing soil complex of all exchange cations by $\mathrm{K}^{+}$or $\mathrm{Ca}^{2+}$ ions markedly increases the sorption of $\mathrm{Cs}^{+}$ions. By reducing the influence on the sorption of the radionuclide by the solid phase of the soil, the cations competing in the soil solution can be arranged in the following order: $\mathrm{Cs}^{+}>$ $\mathrm{Rb}^{+}>\mathrm{NH}_{4}^{+}>\mathrm{K}^{+}>\mathrm{Na}^{+}>\mathrm{Ca}^{2+}>>\mathrm{Mg}^{2+}>\mathrm{Sr}^{2+}$.
Unlike ${ }^{137} \mathrm{Cs}$, the main and only mechanism for the absorption of ${ }^{90} \mathrm{Sr}$ is ion exchange. The behavior of this isotope in soil is determined by the behavior of an isotope carrier (stable $\mathrm{Sr}$ ) and a chemical analogue (stable Ca).

Absorption of this radionuclide by the soil solid phase is closely related to the concentration in the soil solution of other cations. The content of exchangeable $\mathrm{Ca}$ in the soil has a major influence on the uptake of ${ }^{90} \mathrm{Sr}$ into agricultural plants, and the cations on their competitive ability to influence the absorption of a given radionuclide can be arranged in the following order: $\mathrm{Al}^{3+}$ $>\mathrm{Fe}^{3+}>\mathrm{Ba}^{2+}>\mathrm{Ca}^{2+}=\mathrm{Sr}^{2+}>\mathrm{Mg}^{2+}>\mathrm{Cs}^{+}=\mathrm{K}^{+}>\mathrm{NH}_{4}{ }^{+}>$ $\mathrm{Na}^{+}$.

When large quantities of $\mathrm{Ca}^{2+}$ cations are introduced into the soil, as a rule, there is a sharp decrease in the ${ }^{90} \mathrm{Sr} / \mathrm{Ca}$ ratio in the soil solution, which leads to a sharp decrease in the flow of the first to the plants.

As noted by several authors, the concentration in soil solution of anions $\mathrm{PO}_{4}{ }^{3-}, \mathrm{SO}_{4}{ }^{2-}, \mathrm{CO}_{3}{ }^{2-}$ also influences the behavior of radionuclides in the system "soil-plant". Thus, the availability of ${ }^{90} \mathrm{Sr}$ decreases due to the increase in soil solution concentration of $\mathrm{PO}_{4}{ }^{3-}$ anions as a result of the formation of $\mathrm{Sr}_{3}\left(\mathrm{PO}_{4}\right)_{2}$ and $\mathrm{SrHPO}_{4}$ compounds inaccessible to plants.

Many domestic and foreign researchers believe that the main role in the behavior of radionuclides is played by the agrochemical properties of soils. At present, about ten basic parameters are distinguished from all the physicochemical characteristics of soils, which affect the mobility and accessibility of ${ }^{137} \mathrm{Cs}$ and ${ }^{90} \mathrm{Sr}$, which in increasing importance can be placed in the following order: > organic matter content $>$ exchange contents $\mathrm{K}$, $\mathrm{Ca}, \mathrm{Mg}>$ cation exchange capacity $>\mathrm{pH}$.

According to several scientists, the main mechanism of radionuclide movement along the soil profile is the process of diffusion from the zone of high concentration to the zone with lower concentration, transfer in a stream with a fine fraction of soil and transfer in the composition of soluble organic compounds (fulvates and humates) [16, 21, 28, 38].

A significant difference in the mobility of ${ }^{137} \mathrm{Cs}$ and ${ }^{90} \mathrm{Sr}$ in the soil should be noted. As ${ }^{137} \mathrm{Cs}$ can be fixed by mineral components of the soil, their movement along the soil profile is characterized by transfer with fine particles of the soil in a fixed state, whereas $10-40 \%{ }^{90} \mathrm{Sr}$ is bound by the humates of the soil absorbing complex (humic, humatomyelin, and especially fusional forms). Bonding with soil organic matter explains the greater mobility in soils of ${ }^{90} \mathrm{Sr}$ compared to ${ }^{137} \mathrm{Cs}$. A confirmation of the faster ${ }^{90} \mathrm{Sr}$ pre-vision is the increase in the proportion of its exchange forms as it sinks, which is not characteristic of ${ }^{137} \mathrm{Cs}$. For most radionuclides, increasing the humus content in the soil provides a steady decrease in the size of their transition to the plant. According to G. A. Sokolik with colleagues the availability of ${ }^{90} \mathrm{Sr}$ for plants in ionic form is 2-4 times higher than from organomineral complexes. The authors found that the ${ }^{137} \mathrm{Cs}$ transition from humates was 1.3-1.5 and ${ }^{90} \mathrm{Sr} 2-2.5$ times lower than from fulvates.

According to some scientists $[14,33,35]$, the increase of humus content in sod-podzolic sandy 
loam soils from the minimum $(1,0-1,5 \%)$ to the optimum (2.0-3.0\%) was accompanied by a decrease of 1.5 times the ${ }^{90} \mathrm{Sr}$ and $2-5$ times ${ }^{137} \mathrm{Cs}$ in the crop of perennial cereals.

The power and ash content of the peat layer are important factors influencing the intake of radionuclides into the crop of perennial grasses on peat-bog soils. It has been established that the cultivation of peat soils leads to an increase in the mineralization of peat mass (an increase in the ash content) and to a decrease in the radionuclide input into the grass.

In the period from 1986 to 1992 , a stable positive balance of calcium, potassium and organic matter in soils was maintained in the majority of Belarusian farms located in the contaminated radionuclide zone. This, along with other measures, contributed to a significant reduction in the transition of radionuclides to products.

Since 1993, due to economic difficulties, the volume of soil fertility maintenance has declined sharply. This raises the fear of a decline in the rate of improvement of crop production, and in some places exceeds the permissible levels of radionuclide content in forage crops. In some cases, maintaining a higher humus content in the soil $(3,1-3,5 \%)$ may be justified for the radioactive contamination zone in order to further reduce the radionuclide intake in the presence of cheap sources of organic matter (straw, green fertilizers) [31].

The particle size distribution of soils largely determines their absorption capacity and the sorption processes of radionuclides occurring therein. The sorption capacity of soils is directly proportional to the degree of dispersion of the soil particles. The soils of heavy granulometric composition have a larger number of fine fractions than light soils.

K. K. Gedroyts [14] pointed out that the silt fraction of the soil plays a major role in the exchange capacity of soils. The role of larger mechanical soil elements in the physicochemical absorption is small. The soil fraction larger than $0,001 \mathrm{~mm}$ has an absorption capacity from 0,12 to 13,4 mg-eq. per $100 \mathrm{~g}$ soil. Particle fraction less than $0.001 \mathrm{~mm}$ has an absorption capacity from 20,6 to $107,4 \mathrm{mg}$-eq. per $100 \mathrm{~g}$ soil.

Soils containing a large number of fine particles (smaller than $0,001 \mathrm{~mm}$ in size) are characterized by a high absorption capacity. As the particle size decreases, the content of silicon oxide decreases, the amount of one and a half oxides of iron and aluminum increases, and the content of humus and exchange cations of calcium, magnesium and potassium increases (the latter is especially important for radionuclide sorption processes). The smallest dust and silty particles have the highest content of organic matter.

With the reduction of the size of the soil fractions, the strength of their ${ }^{90} \mathrm{Sr}$ and ${ }^{137} \mathrm{Cs}$ strength increases. For example, in the fine sand fraction of sod-podzolic soil and chernozem, $37-45 \%$ of the absorbed amount of cesium remains not displaced after three treatments by ammonium chloride. This indicates that the mineral part of the soil particles is of great importance in the sorption of ${ }^{137} \mathrm{Cs}$.

Dusty fractions have an even greater ability to fix cesium radioactive isotope than sandy ones. Thus, in the silt fraction of soils, the highest amount of ${ }^{137} \mathrm{Cs}$ remains, which are not displaced into the ammonium chloride solution after repeated treatment. From a practical point of view, it is interesting to monitor the distribution of radionuclides by the fractions of contaminated soils. The bulk of ${ }^{90} \mathrm{Sr}$ is concentrated in silty and clayey soil fractions of different types. The clay fraction (less than $0,01 \mathrm{~mm}$ ) accumulates from 50 to $85 \%{ }^{90} \mathrm{Sr}$ of the total soil content. It should be borne in mind that the proportion of different fractions in the particle size distribution of soils is not the same. In addition, differences in the properties of granulometric elements of varying degrees of dispersion are explained by the features of the mineralogical composition. In the clayey and colloidal fractions of soils secondary minerals groups of montmorillonites, vermiculite - predominate. All of them (unlike primary minerals) are characterized by high absorption capacity, including for radionuclides.

According to some researchers, the sorption of radionuclides by soil depends to a large extent on its mineralogical composition. Thus, $98-99 \%$ of the ${ }^{13} 7 \mathrm{Cs}$ concentration in the soil is sorbed by minerals of the montmorillonite group, mica and hydromica. By the ability to absorb and firmly retain ${ }^{137} \mathrm{Cs}$ minerals can be arranged in descending order: ascanite, hydroflogopite, phlogopite gumbrin, vermiculite, bentonite, kaolinite, vivianite, muscovite.

Secondary clay minerals can also be sorbed up to $99 \%$ of ${ }^{90} \mathrm{Sr}$ content in soil. For example, from soil solutions montmorillonite group minerals were absorbed from $92,1 \%$ to $99,9 \%$ of ${ }^{90} \mathrm{Sr}$ content in soil. The kaolinite group minerals were absorbed from $40 \%$ to $68 \%$ of ${ }^{90} \mathrm{Sr}$ content in soil. The mica minerals were absorbed from $71 \%$ to $87 \%$ of ${ }^{90} \mathrm{Sr}$ content in soil. The minerals of the calcite, feldspar and quartz groups were absorbed 10 to $50 \%$ of ${ }^{90} \mathrm{Sr}$ content in soil. Preferably, this radionuclide is sorbed by such minerals as ascanite, bentonite, vermiculite, phlogopite igumbrite. To a much lesser extent, it is sorbed by hydro muscovite and hydrogetite.

In our opinion [27], differences in the completeness of sorption of radionuclides from the soil by different minerals are due, first of all, to the different structure of their crystal lattice. Thus, the minerals of the montmorillonite group (ascanite, gumbrine), as well as the minerals of the mica and hydromica group, due to the structure of the crystalline lattice, have intramicellular absorption (cations entering the crystalline lattice). Therefore, they more fully absorb the micro-amounts of radionuclides from the soil. In addition, these minerals more firmly fix them in the absorbed state compared to the minerals of other groups (kaolinite group). These minerals are characterized by extracellular absorption (absorption of cations on the surface of crystalline lattice layers).

Therefore, the stronger anchoring of ${ }^{137} \mathrm{Cs}$ with soils compared to ${ }^{90} \mathrm{Sr}$ is due, first of all, to the strong sorption of this radionuclide by the mineral part, especially by the highly dispersed fractions containing the minerals of the montmorillonite group and the group of hydro-mica.

The ${ }^{137} \mathrm{Cs}$-free carrier can be absorbed by the soil by sorption of the element on the surface of the three-layer 
minerals. However, it cannot be substituted for hydrogen, sodium, calcium, magnesium or barium ions. Because, these ions not a component of the soil crystal lattice.

${ }^{137} \mathrm{Cs}$ micro-quantities in soil can only be partially replaced by potassium, ammonium and stable cesium. It was also found that the decrease in the availability of ${ }^{137} \mathrm{Cs}$ under the influence of the flagopite and the hydroflagopite is due not only to its strong fixation in the crystal lattice, but also to the content of mobile potassium in this mica.

It should be noted that among the lands contaminated by radionuclides of the Republic of Belarus and Ukraine, more than half are soils of light granulometric composition. Therefore, these soils are characterized by low absorption capacity, low content of humus and secondary clay minerals, increased hydromorphicity and high rates of transition of radioactive substances to agricultural crops. These factors make it difficult to obtain "pure" crop and livestock products (containing radionuclides within the limits of radiation safety).

According to the degree of permeability of radionuclides on the soil profile of different granulometric composition, the following series can be constructed as it decreases: sands, sandy loam, and loam. According to the researchers, the determining factor for the radionuclides from soil to plants is the properties of the soil absorbing complex. The strength of sorption of radionuclides in soil is higher; the greater is its cation exchange capacity and the sum of exchange bases. Strong sorption of ${ }^{137} \mathrm{Cs}$ and high availability of $90 \mathrm{Sr}$ at root admission were noted. Some scientists play a significant role in the absorption of radionuclides $\left({ }^{134} \mathrm{Cs}\right.$, ${ }^{137} \mathrm{Cs},{ }^{85} \mathrm{Sr},{ }^{90} \mathrm{Sr}$ ) by soil parameters such as temperature, $\mathrm{pH}$, and the ratio of liquid and solid phases of soil solution.

It was found that the concentration of ${ }^{90} \mathrm{Sr}$ in meadow plants with decreasing $\mathrm{pH}$ and exchange calcium in alluvial soil decreased. Increasing the fraction of silty fraction in the humus-accumulative horizon above the specified soil type decreased the concentration of both ${ }^{137} \mathrm{Cs}$ and ${ }^{90} \mathrm{Sr}$.

According to many researchers $[33,35], \mathrm{pH}$ is the leading soil factor that determines the mobility and availability of radionuclides. Thus, humic and other low molecular weight acids limit the mobility of radioactive elements. Therefore, the absorption strength of radionuclides by the soil absorption complex, on the contrary, is weakened. The reason due to the formation of negatively charged complex compounds of iron and aluminum with fulvic or oxalic acids. It has been established that soil acidity exerts both direct and indirect acidity on the entry of radionuclides into prairie grasses (changes the cation exchange capacity). However, depending on the physicochemical properties of soils and species differences of prairie plants, the conversion rates of radionuclides into grasses can vary widely (from 0,03 to 79,91 times). Interspecies differences in ${ }^{90} \mathrm{Sr}$ accumulation depending on these properties can reach 30 or more times [30-36].

Thus, the magnitudes of translocation of radionuclides from contaminated soils into plants depend on: 1) the physicochemical properties of soils, 2) the forms of radionuclides in the soil, 3) the basic agrochemical characteristics of soils: a) mineralogical and granulometric composition, b) the content of organic matter and humus, c) soil acidity, d) indicators of the cationic composition of soil solution and soil-absorbing complex (absorption capacity of the degree of saturation of the bases).

In order environmental health of radionuclides' contaminated soil (mainly by ${ }^{137} \mathrm{Cs}$ and ${ }^{90} \mathrm{Sr}$ ), it is important to use the following technologies: 1) localization, 2) deconcentration and 3) inactivation (Fig. 2). At the same time, the techniques of inactivation of these radionuclides should be recognized as a priority technology. For this, information on the behavior and distribution of radionuclides in the soil is very relevant

\section{Conclusions}

In general, modern environmental technologies of healthy soils contaminated by heavy metals and radionuclides are characterized by a considerable variety of action strategies (in-situ, ex-situ) and practical techniques / methods / ways. In extreme cases (very high and extremely dangerous concentrations of these pollutants in soils) it is advisable to use ex-situ technologies for healthy soils. In most cases, in-situ technology should be used for healthy soils. Among these technologies, from an environmental point of view, priorities are localization, deconcentration and inactivation. From an ecological point of view, priorities are extraction of pollutants from the soil. The effectiveness of healthy soils contaminated by heavy metals and radionuclides is conditioned by the skillful application of several technologies.

\section{References}

1. M. Ahmad, S.S. Lee, S.E. Lee, M.I. Al-Wabel, D.C.W. Tsang, Y.S. Ok, Biochar-induced changes in soil properties affected immobilization/mobilization of metals/metalloids in contaminated soils. J. Soils Sediment. 17, 717-730 (2017). doi:10.1007/s11368-015-1339-4

2. R. Alexakhin, S. Firsakova, G. Rauret, N. Arkhipov, Fluxes of radionuclides in agricultural environments: main results and still unsolved problems, in Abstract of the 1st International conference "The radiological consequences of the Chernobyl accident”, vol. 1 (1996), pp. 39-47

3. A.Z. Al-Hamdan, K.R. Reddy, Transient behavior of heavy metals in soils during electrokinetic remediation. Chemosphere 71, 860-871 (2008). doi:10.1016/j.chemosphere.2007.11.028

4. H. Ali, E. Khan, M.A. Sajad, Phytoremediation of heavy metals - concepts and applications. Chemosphere 91, 869-881 (2013). doi:10.1016/j.chemosphere.2013.01.075 
5. B.J. Alloway, Heavy metal in soil (Blackie Academic \& Professional, London, 1994)

6. M.A. Ashraf, I. Hussain, R. Rasheed, M. Iqbal, M. Riaz, A.M. Saleem, Advances in microbe-assisted reclamation of heavy metal contaminated soils over the last decade: A review. J. Environ. Manage 198, 132-143 (2017).

doi:10.1016/j.jenvman.2017.04.060 0301-479

7. S. Askbrant, J. Melin, J. Sandalls, R. Vallejo, T. Hinton, A. Cremers, C. Vandecasteele, N. Lewyckyj, Yu. Ivanov, S. Firsakova, N. Arkhipov R. Alexakhin, Mobility of radionuclides in undisturbed and cultivated soils in Ukraine, Belarus and Russia six years after the Chemobyl fallout. J. Environ Radioact. 31(3), 287-312 (1996)

8. A. Aysen, Problem solving in soil mechanics (Swets \& Zeitlinger, Lisse, 2003).

9. J. Bell, T.H. Bates, Distribution coefficients of radionuclides between soils and groundwater's and their dependence test parameters. Sci. Total. Environ. 69, 297-317 (1998)

10. N. Bolan, A. Kunhikrishnan, R. Thangarajan, J. Kumpiene, T. Makino, M. B. Kirkham, K. Scheckel, Remediation of heavy metal(loid)s contaminated soils - to mobilize or to immobilize? J. Hazard. Mater. 266, 141-166 (2014). doi:10.1016/jhazmat.2013.12.018

11. D.A. Cafaldo, M. Fadden, T.R. Larland, Radionuclide complexation in soils and plants. Special. Fission. and Activ. Prod. Environ. Proc. 85, 398-408 (1986)

12. H.D. Foth, Fundamentals of soil science (John Wiley \& Sons Inc, New York, 1991)

13. C. Garbisu, I. Alkorta, Basic concepts on heavy metal soil bioremediation: review. The European journal of mineral processing and environmental protection 3(1), 58-66 (2003)

14. K.K. Gedroyts, Selected scientific works (Science, Moscow, 1975)

15. M.H. Gerzabek, Wir verhalten sich radioaktive Stoffe im Boden? Agrozucker 4, 9-10 (1996)

16. M.H. Gerzabek, S.A. Mohamad, K. Muck, Cesium137 in soil texture fractions and impact on cesium137 soil-to-plant transfer. Commun. Soil Sci. Plant. Anal. 23, 321-330 (1992)

17. Guidelines for agricultural countermeasures following an accidental release of radionuclides. Technical reports series No. 363 (International Atomic Energy Agency, Vienna, 1994)

18. K. Harmsen, Behavior of heavy metals in soils (Centre for Agriculture Publishing and Documentation, Wageningen, 1977)

19. H. Hu, Q. Jin, Ph. Kavan, A study of heavy metal pollution in China: current status, pollution-control policies and countermeasures. Sustainability 6, 5820-5838 (2014). doi:10.3390/su6095820
20. A. Kabata-Pendias, Trace elements in soils and plants (Taylor and Francis Group, Roca Raton, 2011)

21. J. Kiepul, J. Sieukiewicz, Pobieranie ${ }^{90} \mathrm{Sr}$ i ${ }^{137} \mathrm{Cs}$ przez niektore rosliny ukrawne $\mathrm{z}$ gleb o roznym skladzie mechanicznym. Pamietnik Pulaw 83, 105115 (1994)

22. W. Kuhn, I. Handl, P. Schuller, The influence of soil parameters on ${ }^{137} \mathrm{Cs}$ uptake by plants from long-term fallout on forest clearings and grassland. Health Physics 46(5), 1083-1093 (1984)

23. M. Lu, Z.-Z. Zhang, Phytoremediation of soil cocontaminated with heavy metals and deca-BDE by co-planting of Sedum alfredii with tall fescue associated with Bacillus cereus. Plant Soil 382 (1-2), 89-102 (2014). doi:10.1007/s11104-014-2147-0

24. A. Mahar, P. Wang, R. Li, Z. Zhang, Immobilization of lead and cadmium in contaminated soil using amendments: a review. Pedosphere 25(4), 555-568 (2015)

25. M.M. Mikha, J.G. Benjamin, P.W. Stahlman, P.W.I. Geier, Remediation/restoration of degraded soil: I. impact on soil chemical properties. Agron. J. 106, 252-260 (2014). doi:10.2134/agronj2013.0278

26. J. Paz-Ferreiro, H. Lu, S. Fu, A. Méndez, G. Gascó, Use of phytoremediation and biochar to remediate heavy metal polluted soils: a review. Solid Earth 5, 65-75, (2014). doi:10.5194/se-5-65-2014

27. A.G. Podolyak, S. Tagai, E. Nilova, V. Averin, Assessment of committed doses received by agricultural workers in grain harvesting operations in the areas of radioactive contamination. Radioprotection $\quad 52$ (1), $\quad 37-43 \quad$ (2017). doi:10.1051/radiopro/2017001

28. A.G. Podolyak, A.F. Karpenko, Copper in arable and meadow soils of Gomel region. Ecological Bulletin of Kryvyi Rih District 4, 56-66 (2019). doi:10.31812/eco-bulletin-krd.v4i0.2560

29. V.M. Savosko, Land melioration and phytorecultivation (Dionat, Kryvyi Rih, 2011)

30. V.M. Savosko, Heavy Metals in Soils at Kryvbas (Dionat, Kryvyi Rih, 2016)

31. T. Sawidis, Uptake of radionuclides by plants after the Chernobyl accident. Environ. Pollut. 50(4), $317-$ 324 (1988)

32. H.M. Selim, D.L. Sparks (eds.), Heavy metals release in soils (Lewis Publishers, Boca Raton, 2001)

33. D.L. Sparks (ed.), Soil physical chemistry (CRC, Boca Raton, 1999)

34. D.L. Sparks, Environmental soil chemistry (Elsevier Science, San Diego, 2003)

35. G. Sposito, The chemistry of soils (Oxford University Press, New York, 2008)

36. W. Steffens, W. Mittelsstaedt, G. Klaes, F. Fuhr, Radionuclide transfer of ${ }^{90} \mathrm{Sr},{ }^{137} \mathrm{Cs},{ }^{60} \mathrm{Co}$ and ${ }^{54} \mathrm{Mn}$, to plants grown on soils with different physical and 
chemical properties and from different sites at Eschweilv, in Abstract of the 6th International congress "Radiation, risk, protection", 1984, ed. by A. Kaul et al., vol. 1, pp. 193-196

37. C. Su, L.Q. Jiang, W.J. Zhang, A review on heavy metal contamination in the soil worldwide: situation, impact and remediation techniques. Environ. Skep. Crit. 3(2), 24-38 (2014)

38. T. Szabova, S. Bartha, Stanovenie prechodovych koeficientov pre stroncium $\mathrm{v}$ systeme voda-roslina $\mathrm{v}$ localitach vystavby. Radioactiv. Zivot. Presorted. 8(1), 17-32 (1985)

39. N.V. Timofeev-Resovsky, V.I. Ivanov, V.I. Korogodin, Application of the hit principle in radiobiology (Atomizdat, Moscow, 1968)

40. N.V. Timofeev-Resovsky, A.V. Savich, M.I. Shalnov, Introduction to molecular radiobiology (Medicine, Moscow, 1981)

41. M. Vidal, M. Campas, N. Grebenshikova, N. Sanzharova, Y. Ivanov, A. Rigol, S. Firsakova, S. Fesenko, S. Levchuk, T. Sauras, A. Podolyak, G. Rauret, Effectiveness of agricultural practices in decreasing radionuclide transfer to plants in natural meado. Radiat. Prot. Dosim. 92 (1-3), 65-70 (2000)

42. M.H. Wong, Ecological restoration of mine degraded soils, with emphasis on metal contaminated soils. Chemosphere 50(6), 775-780 (2003). doi:10.1016/s0045-6535(02)00232-1

43. M. Zacchini, F. Pietrini, G. S. Mugnozza, V. Iori, L. Pietrosanti, A. Massacci, Metal tolerance, accumulation and translocation in poplar and willow clones treated with cadmium in hydroponics. Water Air Soil Pollut. 197, 23-34 (2009). doi:10.1007/s11270-008-9788-7

44. S. Zaidi, S. Usmani, B. R. Singh, J. Musarrat, Significance of Bacillus subtilis strain SJ-101 as a bioinoculant for concurrent plant growth promotion and nickel accumulation in Brassica juncea. Chemosphere 64, 991-997 (2006). doi:10.1016/j.chemosphere.2005.12.057

45. J. Zhang, J. Liu, R. Liu, Effects of pyrolysis temperature and heating time on biochar obtained from the pyrolysis of straw and lignosulfonate. Bioresour. Technol. 176, 288-291 (2015). doi:10.1016/j.biortech.2014.11.011

46. S. Zhang, M. Chen, T. Li, X. Xu, L. Deng, A newly found cadmium accumulator - Malva sinensis. Cavan. J. Hazard. Mater. 173, 705-709 (2010). doi:10.1016/j.jhazmat.2009.08.142

47. F. Zhao, E.Lombi, S. McGrath, Assessing the potential for zinc and cadmium phytoremediation with the hyperaccumulator Thlaspi caerulescens. Plant Soil. 249(1), 37-43 (2003). doi:10.1023/A:1022530217289

48. R.L. Zheng, C. Cai, J.H. Liang, Q. Huang, Z. Chen, Y.Z. Huang, H.P.H. Arp, G.X. Sun, The effects of biochars from rice residue on the formation of iron plaque and the accumulation of $\mathrm{Cd}, \mathrm{Zn}, \mathrm{Pb}, \mathrm{As}$ in rice (Oryza sativa L.) seedlings. Chemosphere 89,
856-863

(2012).

doi:10.1016/j.chemosphere.2012.05.008

49. Q.X. Zhou, S. Cui, S.H. Wei, W. Zhang, L. Cao, L.P. Ren, Effects of exogenous chelators on phytoavailability and toxicity of $\mathrm{Pb}$ in Zinnia elegans Jacq. J. Hazard. Mater. 146, 341-346, (2007). doi:10.1016/j.jhazmat.2006.12.028

50. F. Zojaji, A.H. Hassani, M.H. Sayadi, Bioaccumulation of chromium by Zea mays in wastewater-irrigated soil: An experimental study. Proc. Int. Acad. Ecol. Environ. Sci. 4(2), 62-67 (2014)

51. M. Zubair, M. Shakir, Q. Ali, N. Rani, N. Fatima, S. Farooq, S. Shafiq, N. Kanwal, F. Ali, I.A. Nasir, Rhizobacteria and phytoremediation of heavy metals. Environ. Technol. Rev. 5, 112-119 (2016). doi:10.1080/ 21622515.2016.1259358 